\title{
Intimate Partner Violence Impacts University Students in Ghana
}

\author{
By Margaret Ivy Amoakohene* \\ Marquita Smith ${ }^{\dagger}$ \\ Gilbert K. M. Tietaah
}

\begin{abstract}
Intimate partner violence cuts across cultures and types of relationships. While the phenomenon has received considerable academic attention in many contexts, few scholarly works exist in Ghana. This research project was limited to tertiary level students at Ghana's premier university. The study, using open-ended qualitative questions, examined the phenomenon from a multidimensional perspective as it affects both male and female in dating relationships. Additionally, the study attempts to fill a gap in the literature by examining abuse in relationships between largely unmarried intimate partners in a university. It also pushes beyond the academic realm and offers a guide for practice, by establishing a public relations campaign targeted to the university students. Researchers investigated the scope and types of intimate partner violence among students in dating relationships, students described experiencing physical and emotional abuse, citing reasons for continuing non-healthy relationships. This study seeks to understand why university-educated victims remain in abusive relationships.
\end{abstract}

Keywords: abusive relationships, dating relationships, Ghana, Intimate partner violence, university students.

\section{Introduction}

Civil society leaders and government officials around the world continue to announce that violence against women and girls is a human rights matter. From a policy concern, the persistence of domestic violence threatens the achievement of gender equality, and for Ghana it presents a challenge in achieving the Sustainable Development Goal 5 of gender equity. Moreover, domestic or partner violence results in poor emotional and physical health, along with higher risks of sexually transmitted diseases, decline in human development and lower productivity (Garcia-Moreno et al. 2006, Moosa 2012). In 2008, 38.7 of ever-married Ghanaian women between the ages of 15 and 49 had experienced physical, emotional or sexual violence by a husband or partner at some point in their lives. Although much of the information and policies on domestic violence focus on women and girls, men and boys were also affected. In fact, a number of Ghanaian males have reported experiencing physical or emotional violence perpetrated by their wife or

\footnotetext{
"Senior Lecturer, Department of Communication Studies, College of Education, University of Ghana, Ghana.

${ }^{\dagger}$ Associate Professor, Department of Communication, John Brown University, USA.

Lecturer, Department of Communication Studies, College of Education, University of Ghana, Ghana.
} 
partner. The purpose of this qualitative study, however, is to provide an in-depth understanding of partner/domestic violence in Ghana and what messages are communicated resulting in such violence, particularly among university students. It is our hope that this project will increase advocacy, promote policy and education, countering such violence in Ghana.

The World Health Organization (2012) defines intimate violence in terms of behavior that results in physical or psychological harm to a partner in the relationship. Wingood et al. (2000: 270) also define intimate partner abuse as 'physical or sexual assault by a husband, intimate partner, or ex-intimate partner. In reality, the most common perpetrators of violence against women have been found to be male intimate partners or ex-partners although women are sometimes also violent (WHO 2012). Previous research indicates that women are both victims and perpetrators of intimate partner abuse, a phenomenon which occurs in all settings and among all socioeconomic, religious and cultural groups (Amoakohene 2004, Appiah and Cusack 1999) making it widespread in all countries (WHO 2012). According to Truman and Morgan (2016), the U.S. Bureau of Justice Statistics showed 57.9 of IPV cases in 2014 and 54.1 in 2015. As one of the most common forms of violence against women, it includes physical, sexual, and emotional abuse as well as controlling behaviors by an intimate partner (GarciaMoreno et al. 2006).

McHugh and Frieze (2006: 121), however, note that widespread changes have occurred, in the consciousness of people regarding intimate partner abuse dating back to the 1970s when feminists called attention to the problem of husbands beating their wives. They further indicated:

Over the past 35 years, approaches to domestic violence have evolved from viewing the problem as limited to a very few problematic marriages, and disbelieving and blaming battered women, to recognizing the prevalence of serious levels of physical violence and psychological abuse in many intimate relationships (p. 121).

The researchers found that early conceptions of the phenomenon centered on the initial focus of physical violence experienced by married, heterosexual women hence the use of such terms as "wife abuse" and "domestic violence." They have, however, noted differences in their conceptualization.

In Ghana, as elsewhere, only a few studies (Appiah and Cusack 1999, Amoakohene 2004) have documented intimate partner abuse among married women. However, no known study has documented or reported on abuse while dating or in unmarried relationships. The present study attempts to fill that void by examining abuse in relationships between largely unmarried intimate partners at the tertiary or university level. Since Amoakohene's (2004) study, governmental (principally the Ministry of Gender, Children and Social Protection and the Domestic Violence and Victim Support Unit [DOVVSU] of the Ghana Police Service) and non-governmental organizations have engaged in interventions to limit the violence in Ghana. Focused on students at a Ghanaian university, our study sought to investigate the scope and types of intimate partner violence among 
students in dating relationships. It also sought to understand if, and why, victims might continue in such relationships in spite of their high educational levels.

\section{Literature Review}

A review of the literature on intimate partner relationships showed the prevalence of violence against women, especially within western societies (GarciaMoreno et al. 2006) is well documented. In comparison, efforts to document the situation in developing nations were less common (WHO 2012, Amoakohene 2004, Jewkes 2002). Amoakohene's (2004) study reported and discussed perceptions of educated, married and employed women in Ghana of acts of violence in marriages as well as policy responses available to protect victims. She identified similarities and differences in the types of violence suffered by women irrespective of their education or socioeconomic standing. The women regarded intimate partner violence as normal occurrences in marriage relationships, and consequently, victims of such abuses were unlikely to report violent acts to law enforcement agencies. This behavior was attributed to socio-cultural constructions of the Ghanaian society which appeared to disapprove of them reporting the acts of violence. Government and civil society organization interventions, sensitizing and educating women to distinguish between culture and human rights, played a minimal role in curbing violence.

On the contrary, statistics from the Domestic Violence Unit of the Ghana Police Service, however, show an increasing trend of female-to-male violence. The Unit's 2013 statistics showed 770 reported cases of husband or male partner victims of physical abuse, an increase from 725 or 6.2 in 2012. In 2014, those numbers skyrocketed to 3,143 cases or 75.5 of male physical abuse. In 2015 that number decreased 2,807 or $12 \%$. Most of these incidents occurred during Christmas, Easter and other festive seasons as well as the re-opening of school. Domestic violence officials observed that money for school fees and for purchasing new items usually generated arguments that triggered assault. Moreover, Jewkes observed that one of two factors, "the unequal position of women in a particular relationship (and in society) and the normative use of violence in conflict" (2002: 1426) worked together with others to cause intimate partner violence. She disclaimed survey findings that suggested social and demographic features, including age and education, as risk factors associated with the phenomenon. Instead, she identified poverty as an exceptional demographic factor associated with increased risk of intimate partner violence.

\section{Students Report IPV Situations}

One area of focus on intimate partner violence (IPV) for researchers has been the nature and attitudes of college students towards IPV. Employing the "bystander model," Branch et al. (2013) in a survey involving freshmen college students discovered that about 54\% were likely to report IPV should they witness a friend or colleague suffering it. This finding was an illustration of the 
assumption that by equipping students with information on how to recognize the symptoms of IPV and whom to report such issues to, they were likely to report it if they realized that a friend was experiencing it.

Katz et al. (2011) found that high school students who had been exposed to the Mentors in Violence Prevention (MVP) - assumptions of this model are similar to those of the bystander model - were more likely to intervene and report whenever they encountered situations involving more aggressive types of behavior. In the survey, they employed the Likert-type scale and asked students questions such as how wrong they considered certain actions such as "telling jokes that make fun of women and girls" and how likely they were to take action to stop such a behavior.

Koelsch et al. (2012), in focus group discussions, studied the likelihood of university students intervening to prevent the perpetuation of sexual violence during parties. They discovered that although most of the participants in the study, male students in particular, believed it was the responsibility of women to ensure their safety and that of their friends at parties. The study revealed that most students were armed with intervention strategies such as reporting the incident to the authorities, and they were willing to engage these strategies as bystanders.

\section{Students Experience Various Forms of IPV}

Investigating types of IPV students suffered, consequences and predicators of IPV, Umana, Fawole and Adeoye (2014) studied the prevalence of IPV among students of University of Ibadan, Nigeria. After surveying female students who resided in hostels on campus, the researchers estimated that the prevalence lifetime of IPV experience was $42.3 \%$, with majority of the students $(41.8 \%)$ reporting that they had suffered psychological abuse; $7.9 \%$ and $6.6 \%$ reporting physical and sexual violence respectively. Types of physical injuries sustained included cuts, punctures, bites (55\%); scratches, abrasions, bruises (48.3\%); sprains, dislocations (18.3\%), while psychological effects of IPV experienced included loss of concentration $(71.1 \%)$, loss of self-confidence $(68.9 \%)$ and school absenteeism $(56 \%)$. The study also established a correlation between respondents who used substances such as alcohol or cigarettes experienced inter-parental violence and their attitudes towards IPV. According to the researchers, these persons were more likely to suffer IPV than their counterparts; making drugs - alcohol and cigarette and inter-parental violence experiences predictors of IPV.

Kordom and Arunachallam (2014), like Umana et al. (2014), conducted a study into the prevalence and socio-demographic factors associated with IPV among undergraduate nursing students in a South African tertiary institution. Their survey discovered that students suffered psychological abuse as the highest type of abuse (65), followed by financial abuse (39), physical abuse (34) and sexual abuse (23) 12 months before the study. Contrary to most research findings which suggest that survivors of IPV are usually young, Kordom et al. (2014) discovered that respondents within the 35-44 age brackets experienced more IPV than other age groups. They argued that this finding could be due to the fact that 35-44-year-olds 
were either married, cohabiting, separated or divorced - all of which are risk factors of IPV - while younger women, although dating, were relatively young, unmarried and still under the protection of their parents.

Barrick et al. (2013), in an online survey, examined which IPV types were prevalent among students from various racial groups in Historically Black Colleges and Universities (HBCUs), and the correlation between certain demographic characteristics and other IPV risks and experience of IPV among these students. Their study revealed that about $64 \%$ of the respondents had experienced IPV at least once in the year before the study was conducted. Of this percentage age, the majority (63.7) identified verbal or controlling IPV such as yelling, screaming, and insulting, 17.8\% reported experiencing physical forms of IPV such as hitting, slapping, and pushing, and about $1 \%$ reported having suffered sexual assault. Contrary to Kordom et al. (2014), Barrick et al. (2013) found that younger students, more than older ones, were more likely to report IPV victimization. Also, compared with married women or those in a form of domestic relationship, single women were less likely to report experiencing any IPV type. Similar to Umana et al. (2014), Barrick et al (2013) reported that women who indicated use of some illicit drug other than marijuana since entering college were more likely to experience physical and sexual violence; thereby making use of illicit substance a risk factor for IPV. Like Nabors and Jasinski (2009), Barrick et al. (2013) discovered that women who had violence socialization, specifically sexual assault victimization, were more likely to experience a form of IPV when they got to college. Thus, the literature shows similar trends in intimate partner violence across different demographic settings and presents a base to study, analyze and explain current trends in intimate partner violence among university students in developing countries, particularly in places like Ghana where patriarchal cultural norms often define social relations among men and women.

\section{Methodology}

Centered on language and words, focus group methodology is labeled qualitative (Creswell 2007). Researchers highlight themes or perspectives, and should use specific methods to analyze patterns during the conversation (Creswell 2007). In our study, 20 focus group discussions were held over a two-week period in April 2015. One half (10) of the groups were composed of females; the other half comprised male students. Most of the participants were undergraduate students. Included also were 10 postgraduate students with ages ranging from 20 to 30 years. The number of participants in each group ranged between six and $10 \mathrm{a}$ respectable standard of practice (Amoakohene 2005, Bernard 2006). Focus group conversations occurred at one of Ghana's largest public institutions. Participants were engaged in their campus living spaces to create a more comfortable environment for discussions.

Qualitative designs require a sampling strategy to assist researchers in deciding what questions to ask and whom to ask (Lindolf and Taylor 2002). Groups were fairly homogeneous, consisting of students of the same sex, age 
group, and academic levels, purposively selected to enable group synergies. Thus composed, the groups enabled participants to discuss abuses in their relationships more openly and candidly with no discernable limitations on personal disclosures even of their own involvement as perpetrators. Additionally, students were selected using both purposive and snowball sampling which involved participants recommending colleagues they knew to be in abusive relationships for inclusion in the study. In fulfillment of ethical disclosure obligations, the rationale for the study was carefully explained to would-be participants.

According to Lincoln and Guba (2000), credibility (vs. internal validity) refers to the idea of internal consistency, where the concern is ensuring rigor (Gasson 2004: 95, Lincoln and Guba 2000). To increase credibility, researchers used thorough descriptions of source data and the emerging analysis (Geertz 1983). To further ensure candor, we acquired consent and offered focus group participants complete confidentiality. In each group, the 40-50-minute discussion was recorded. Each session was moderated by one researcher. Audio recordings of the discussions were subsequently transcribed for thematic analysis (Creswell 2008). The institutional ethics board approved the research process.

Focus group participants had been in relationships lasting between six months and five years. The majority of the participants had on average, about three relationships each. The average age difference between participants and their partners was five years. Apart from one participant who had had two children with her partner and another who had one child, no other participants had children. Many of the participants had partners outside the university campus (popularly called 'exter' or 'externals') but saw them frequently. There were many, though, whose boyfriends and girlfriends attended the university, a phenomenon generally referred to as 'inter' or 'internals.' One female participant had been married for a year.

\section{Findings}

In order to provide an in-depth understanding of intimate partner violence among university students, we discussed salient issues concerning forms of abuse/violence with participants. Abuse ranged from threats, blackmail, and financial exploitation to physical assaults. Participants also reported emotional or psychological abuse in the form of insults, uncharitable remarks and disinterest by partners. Group members also discussed the role of sex in their relationships. In fact, male participants reported that they were mostly in intimate relationships because of sex, companionship and comfort. Meanwhile female participants were primarily in the relationships for companionship, comfort, affection, attention, security and financial benefits. For these participants, any assaults on status and expectations often constituted abuse. Many of the female participants were victims of abuse in their relationships, however; a few admitted they were perpetrators. Similarly, the majority of male participants were perpetrators, but a few reported that they were also victims. 


\section{Participants Face Emotional/Psychological Abuse}

Those who said they suffered emotional or psychological abuse cited insults and/or uncomplimentary comments from their partners. Some expressed disinterrestedness in the relationship which caused one partner to wonder about the other partner's love and commitment. Although no male participant admitted to being emotionally or psychologically abused, it was clear from some of the female participants that they sometimes intentionally passed their partners through some "emotional torture." Not only did they find such cases risible, they also felt it as pay-back for accumulated wrongs suffered. In one very revealing situation, a female participant who appeared to have support of the group said:

What is the big deal if they also go through pain? After all, we (females) go through pain almost on a daily basis. If I can't beat him physically or hit him I also have my trump card and I never fail to use it to my own advantage. I know he loves me to bits and will not dare to leave me. ... What he hates is to find me with another boy or see me chat heartily with any other boy. So, that is exactly what I do when I want to pay him back for anything he does wrong...

However, for some female participants, emotional abuse was the worst form of abuse one could experience. They believed that was the form of abuse that touched on one's "inner self," and had the capacity to destroy one's own conception of who she or he is. According to some participants, emotional abuse was "a silent torture" which undermined one's ego and self-worth. One participant, who had resolved to remain single because she suffered so much emotional abuse in all her previous relationships said:

...I prefer to stay single because guys have always abused me emotionally in the past. The emotional torture alone, my sister ... it's not easy at all. ... My immediate ex would not go anywhere with me. He won't introduce me to anyone as his girlfriend, he won't make me feel special in anyway - no gifts, no outings, you know, the hide and seek kind of thing. It was emotionally so hurting that I always felt less of a lady.

\section{Women Encounter Threats and Blackmail}

Some participants, mainly females, reported receiving threats from and being blackmailed by their partners while others expressed fear of losing their lovers. Another female participant who felt threatened and was blackmailed by her partner, said any time they had disagreements he threatened to publicize some naked photographs of herself she had earlier sent to him.

There was this time when I was in level 200 that I sent him some naked pictures of myself. I don't even know why I did that thing but well we had just started dating and it was one of those days. I was in a crazy mood, I was 
home and I'd missed him. I guess I thought he was going to delete them after watching or something. But he says he just looks at them when maybe he's horny and I'm not around or something. But now, anytime we argue he goes like if I leave he will make sure everybody sees those pictures. He'll disgrace me and I'm like geez that's so immature.

Male participants often equated manipulation to abuse. They mentioned girlfriends alleging pregnancy and withholding sex. Meanwhile, women described major threats of death and slander.

\section{Women Undergo Financial Abuse}

Financial abuse was reported in several intimate relationships. Abuse was largely reported by females citing cases where their male partners sought to take advantage of their resources, especially money, forcing them to share their meager incomes and/or allowances. A number of female participants who narrated such instances said they felt financially abused by their partners. According to one of them:

I was still quite young, I was only 17, and my friends were having boyfriends so I also wanted to have a boyfriend. I started a relationship, and the guy was then 25 years old. Imagine the age gap so he was kind of like my big brother so I was always answerable to him. By then my parents used to give me my monthly allowance because I was already in school. This guy will expect me to give him money because he would tell me that he is not financially independent so he needed my financial support. I would be so emotional and willing to help him so I would divide my allowance into two and give him half. There is no way I would give him $48 \%$ and take $52 \%$ because he would not allow me. This went on for years until a particular day that my parents didn't give me money because I did something wrong so I went to him and told him that this month there is no money.

Another participant who had suffered financial abuse reported that:

I have never been physically abused but financially, I have been abused. When I was dating my last guy, he said he was not from a rich home. I will send him money but he never gave me anything when I was in need and he would ask me to call my parents. When we go out together, he makes me pay but later I found out that he had money. It still continued for a long time and I noticed something when he sees something new with me. For example, my father bought me a blackberry, he came all the way from his school, which is three hours journey to come and complain about the people I will call. The next week he also bought a blackberry. So, I asked him where he got the money from and he said he got it from his friends... Then, when someone sends me a message or I use a friend as my profile on Facebook, he will come all the way from his school to insult me and that was part of the reason I ended the relationship. 
For university students, financial resources help with retention and persistence. When partners financially abuse students, this can directly impact academic performance.

\section{Physical Violence Plagues Participants}

Physical violence was also prevalent in the discussions. Participants described physical assaults, including at times forced sexual engagement. More than often women were the victims of this abuse, but in a few instances, men were physically harmed. A male participant who felt jealous and justified in assaulting his partner said:

My partner got me really angry once. She was giving a lot of attention to this other guy and when I confronted her she said they were just friends. One time I went to her room, and he was there on the bed. After he left I raised the issue and she asked me what my problem was. I grabbed her and pushed her onto the floor.

Another male participant admitted to slapping his partner once for referring to him as a greedy person. He recounted:

...yes, I have ever slapped my woman. She said I was greedy. That was the first time I physically assaulted her but I'm not sure that will be the last time. She has a loud mouth... it's likely to happen again...

He too had been a victim of abuse in their relationship suggesting that they might be a violent pair. According to him: "...When she gets mad [angry], she throws things at me but I manage to dodge. She hasn't gotten me yet." Despite the suffering that many endured, several participants believed they deserved the poor treatment. A female victim of physical abuse (slapping) claimed it was her fault that she was abused, explaining that: "We were arguing and I kept reminding him of certain personal things that really hurt and I guess he just lost it. He actually slapped me; but it was partly my fault."

Several female participants who mentioned abortions, remorsefully, said their partners hit and raped them anytime they refused to have sex with them and often did not use a condom. Another revealing situation of sexual abuse was one female participant whose partner incessantly demanded for anal sex. The student explainned:

...Mine was in a past relationship. Well, I experienced this abuse in my very first relationship, the guy used to always try to have anal sex with me. The first time he tried, I cried because it was so painful, but he wouldn't let go. Honestly, that was the main reason why I left him. I mean I just think a guy who can do that is a gay. It was absolutely disgusting. I've heard of people putting on diapers because of these things, and I certainly didn't want to get there at all. After all we were not married. 
While not as violent, a few male participants said they felt sexually abused in their relationships. As one of them put it:

My girlfriend almost always demands for sex whenever we meet, and we have been battling with this issue over a long period of time. I really feel I'm being abused in this relationship. It is as if I am only useful as a sex machine.

The issue of sex in relationships was discussed openly within the groups. Many did not see premarital sex as a problem because they thought they were old enough to determine for themselves what they needed in their relationships. Some male participants said they felt rejected when denied sex by their partners and interpreted that as abuse of their rights in the relationship. Many of them usually saw this as a punishment inflicted by their female partners especially when they felt aggrieved. One participant said his partner often used this form of "punishment," whenever they had disagreements and this often led to abuse. Another male participant said he once abused his partner when she denied him of sex:

Oh yes, I have abused her several times and usually because of her excuses when it comes to sex. I will give you an example. Once she came to my place and, fortunately, nobody was in the room. It was just the two of us. However, as always, it was one excuse after another. Of course, I got fed up. I just pushed her from the room. I told her to leave my room. I pushed her out, and she fell in the process.

One recurring complaint of female participants was their partners demanding sex even during their menstruation periods. One participant said:

...in my case, my boyfriend sometimes wants to make love to me even when I'm in my menses. But I've spoken to him about the health hazards, and he has agreed to stop so I hope I don't have that issue anymore.

\section{IPV Means Life and Death}

Women described emotional and physical assaults including rape. But at least two female participants spoke about receiving death threats from a partner. One received a death threat from a partner who was suspicious of her leaving him.

There was this time my boyfriend for reasons best known to him thought I would leave him. We had gone out and he was dropping me at home. He started to say that he had put his all into the relationship and that I shouldn't disappoint him. He actually knelt in front of me and I told him he was being ridiculous and I guess that pissed him of course he told me that if I ever cheated on him one of us would die.

This situation, she reckoned, put her in fear of her partner and finally contributed to ending the relationship. Another female participant said: 
He keeps saying he will kill me if I leave him. He goes like he's invested so much time and money in me so if he can't have me, he won't leave me alive for those small, small boys to come after me. ... My father died when I was in SHS [Senior High School] and he takes very good care of me. He has even opened a shop for my mom in front of our house. And so, he's always rubbing it in. Anytime there's a problem, he'll start reminding me of the things he does for my family and stuff.

Participants shared intimate details of their personal, and at times, abusive relationships. The conversations recounted events that occurred prior to the focus group conversations and this study.

\section{Women Share Reasons for Enduring Abusive Relationships}

For most participants, there was no reason why they would remain in abusive relationships. However, for the hesitant, several reasons were given to justify why they stayed. Some participants gave love (whatever its definition and how they understood it) as a reason while others still felt comfortable in spite of the occasional abuse. For yet others, the fear of being maimed by an abusive partner if they decided to quit was sufficient to keep them in those relationships. Financial benefits, apart from familiarity with their partners, were by far the most important reasons why most female participants would not leave abusive relationships thereby underscoring the dependency syndrome. According to one participant:

I think the devil you know is better than the angel you don't know, but my main reason is the financial support I get. At this age, I can't go asking my parents for money for all my needs so my boyfriend supports me.

Another confirmed the importance of financial support from male partners:

My boyfriend is virtually the one footing my master's program.

After my national service, I wasn't getting any job, and I thought of coming back to school but I had no money, and he offered to foot my bills and see me through school. So, I stay with him.

Another female participant who had similar reasons for staying said she would rather stay and try to make the relationship better:

...Well I guess it's because of the reality that there's really nothing like a perfect relationship so I just weigh the good and bad sides and figure that aside the trashy hurtful things he says sometimes, he's still a good person. Everyone has his bad sides. This just happens to be his so I just try to live with it.

In a few cases, some especially female participants, will not leave their abusive relationships because of the influence and support of their parents for their 
male partners and for the relationship. According to one female participant who just could not imagine herself leaving the relationship:

I can't just leave him. My parents really like him. They think he'll make a cool husband. And my mum's always backing him when we have a misunderstanding. She's always saying that there's nothing like a perfect man so I have to compromise and learn to live with him like that.

Male participants provided a different perspective regarding why they felt compelled to stay in their relationships. While some reported they were happy with their partners, in spite of occasional abuse, others simply felt no need to quit because quitting would be a waste of time. According to one such male participant who had been in his current relationship for five years: "Well... having come this far, I think it would be a waste of time to break up and start a new relationship." After all, "all women are the same." Another male participant said:

I still love my girlfriend, and I think I will be better off with her than entering into a new relationship. After all, it is said that the devil you know is better than the angel you don't know.

It was revealing that in a few cases, participants believed that despite the abusive nature of their partners, they would still make good marriage partners. According to one male participant:

Yes, we're having fun. Aside her loud mouth, I will say she will be a good home wife in the future because of the way she cooks and also attends to my needs when I am in a tight corner.

For participants who had children, the involvement of children in a relationship and the hope of things getting better were also given as reasons for staying in abusive relationships. A female participant who had a child with her abusive partner said she was still in the relationship for the sake of the child. However, many female participants expressed the need for women to be assertive in relationships and have the courage to quit abusive relationships.

\section{Discussion}

While the college women in our study did exhibit some harmful, mean, behaviors, the women also experienced IPV more often and more extreme measures of abuse than males. Did perpetrators see abuse differently? Many of the participants who were perpetrators of abuse claimed that what they did were not acts of aggression but only reactions to provocative actions and words from their partners. In some cases, the perpetrators recognized that their actions constituted abuse but, instead of showing remorse or regret, they believed they had good reason for doing what they did. For example: 
The first time I hit her, we had just returned from the cinema and all she said was you wasted my time, instead of showing appreciation. Meanwhile, she was the one who requested that we go to the cinema in the first place. I was furious.

The literature 'suggests that different types of violence often coexist': physical abuse is often accompanied by sexual abuse, and then by emotional abuse (WHO 2012: 2) though more than a quarter of intimate relationships involve at least an incident of physical assault (McHugh and Frieze 2006). The findings of this study corroborate those findings as various forms of abuse were identified by participants: ranging from verbal, emotional, psychological, and financial to physical. Most forms of abuse ended in physical assault of partners, which was consistent with an earlier study on violence against women in Ghana (Amoakohene 2004).

Additionally, the findings of the present study showed that almost all the female participants had experienced some form of sexual abuse in their relationships with only a handful of males reporting such incidence. Emerging themes such as threats, financial exploitation, physical, verbal, emotional, psychological and sexual abuse corroborate findings of earlier studies conducted in Ghana (Appiah and Cusack 1999, Amoakohene 2004). Whereas participants in the present study openly talked about sex, in those previous studies sex appeared to be a taboo subject. Perhaps participants' education and the collegial atmosphere coupled with intensified coverage (education and discussion) of sex in television, radio, cinema and other media could account for this change. Whereas in Amoakohene's (2004) study most women did not consider rape as an offense within marriage, some participants in the present study reported instances of rape as detestable in their relationships. The findings of this study highlight the importance of sex, especially to male participants who saw a denial of sex as an offense and an abuse of their rights.

Heise et al. (1999) provide various reasons why women may stay in abusive relationships including: fear of retaliation, lack of alternative means of economic support, lack of support from family and friends, stigma or fear of losing custody of children associated with divorce; and love and the hope that the partner will change (cited in WHO 2012: 3). Findings of this study largely corroborate the above conclusions as to why people, particularly women, continue to stay in abusive relationships. That participants would not quit because of love, financial support (dependency), familiarity (the devil you know ... syndrome), comfort despite abuse, a waste of time, influence of parents and/or family, children in the relationship, and hope of things getting better, influence decisions to stay in abusive relationships.

Most participants believed that although some instances of abuse were bound to occur in relationships, people should decide for themselves when it is time to quit. Still, participants acknowledged that repeated and/or aggravated abuse signaled the end of the relationship. A female participant concluded that:

When you've been abused repeatedly, especially when it's physical, then you 
have to get out. Being in a relationship is good. You have someone who cares about you and does things for you. If you're happy you stay. If you are unhappy, simply get out!

Another female participant said:

...such people should leave such relationships because they are unhealthy relationships and obviously, the person has no respect for you. You will never know what this person can do to you in the future.

The focus groups showed a hesitancy to label situations as IPV, but all perceived IPV as unacceptable aggression.

\section{Conclusion}

The study suggests that educational level does not necessarily mitigate intimate partner abuse. In fact, individual needs for love, and financial and emotional support were reported as reasons for sustaining abusive relationships. Generally, male partners were mostly perpetrators while female partners were predominantly victims; however, there were a few female participants who reported verbally, emotionally and, sometimes, physically abusing their partners. Those women reflect current trends. The Domestic Violence Unit shows a rise in female-to-male violence in Ghana. This trend suggests that abuse may just be a human phenomenon although more males than females are still recorded as perpetrators. Given these observations, future studies may want to examine how widespread the phenomenon of female-to-male violence is as well as isolate factors which engender intimate partner abuse, including the role of the media and communication messages.

A practical recommendation would be for institutions to develop strategic communication plans to increase awareness of IPV among students. A short-term goal of the plan is to raise awareness and educate college students about IPV, specifically to recognize what IPV looks like in real-life situations and to understand the severity of IPV. Creative arts could be used to help educate communities. Using live theatre as the method to educate about IPV is not a new idea, but instead is one that has been successful in the past, enabling discussion about issues that are uncomfortable and that "individuals might otherwise find threatening or prefer to avoid" (Dill-Shackleford et al. 2015: 970). Previous studies about the effectiveness of an education-entertainment campaign found that, not only were the unintended effects of a public relations campaign lessened, but also: "Those who watched a play about abusive relationships not only demonstrated greater knowledge about relationship abuse than controls but were also less likely to endorse myths about relationship abuse" (Dill-Shackleford et al. 2015: 973). While university students experienced a varied range of intimate partner violence, research suggests that stronger educational efforts can decrease the number of young people impacted by intimate partner violence. 


\section{References}

Amoakohene MI (2004) Violence against Women in Ghana: A Look at Women's Perceptions and Review of Policy and Social Responses. Social Science \& Medicine 59(11): 2373-2385.

Amoakohene MI (2005) Focus Group Research: Towards an Applicable Model for Africa. In K Kwansah-Aidoo (ed), Topical Issues in Communications and Media Research, 173-197. New York: Nova Science Publishers.

Appiah DC, Cusack K (1999) Breaking the Silence and Challenging the Myths of Violence against Women \& Children in Ghana. Report, Accra: Gender Studies and Human Rights Documentation Centre.

Barrick K, Krebs CP, Lindquist CH (2013) Intimate Partner Violence Victimization among Undergraduate Women at Historically Black Colleges and Universities (HBCUs). Violence against Women 19(8): 1014-1033.

Bernard HR (2006) Research Methods in Anthropology: Qualitative and Quantitative Approaches, $4^{\text {th }}$ ed. Lanham: AltaMira Press.

Branch KA, Richards TN, Dretsch (2013) An Exploratory Analysis of College Students' Response and Reporting Behavior Regarding Intimate Partner Violence Victimization and Perpetration among Friends. Journal of Interpersonal Violence 28(18): 3386-3399.

Creswell JW (2007) Qualitative Inquiry \& Research Design: Choosing among Five Approaches, $2^{\text {nd }}$ ed. Thousand Oaks, CA: Sage Publications.

Creswell JW (2008) Educational Research: Planning, Conducting, and Evaluating Quantitative and Qualitative Research, $3^{\text {rd }}$ ed. Upper Saddle River, NJ: Pearson Education.

Dill-Shackleford KE, Green MC, Scharrer E, Wetterer C, Shackleford LE (2015) Setting the Stage for Social Change: Using Live Theater to Dispel Myths about Intimate Partner Violence. Journal of Health Communication 20(8): 969-976. doi:10.1080/ 10810730.2015.1018622.

Gasson S (2004) Rigor in Grounded Theory Research: An Interpretive Perspective on Generating Theory from Qualitative Field Studies. In ME Whitman, AB Woszczynski (Eds) The Handbook of information Systems Research, 79-102. Hershey, PA: Idea Group.

Garcia-Moreno C, Jansen HA, Ellsberg M, Heise L, Watts CH (2006) Prevalence of Intimate Partner Violence: Findings from the WHO Multi-country Study on Women's Health and Domestic Violence. The Lancet 368: 1260-1269.

Geertz C (1983) Local Knowledge: Further Essays in Interpretive Anthropology. New York, NY: Basic Books.

Heise L, Ellsberg M, Gottemoeller M (1999) Ending Violence against Women. Baltimore, MD, John Hopkins University School of Public Health, Center for Communications Programs.

Jewkes R (2002) Intimate Partner Violence: Causes and Prevention. The Lancet, 359: $1423-29$.

Katz J, Heisterkamp HA, Fleming WM (2011) The Social Justice Roots of the Mentors in Violence Prevention Model and its Application in a High School Setting. Violence against Women 17(6): 684-702.

Koelsch LE, Brown AL, Boisen L (2012) Bystander Perceptions: Implications for University Sexual Assault Prevention Programs. Violence and Victims 27(4): 563579.

Kordom A, Julie H, Arunachallam S (2014) Intimate Partner Violence amongst 
Vol. 6, No. 1 Amoakohene et al.: Intimate Partner Violence Impacts University...

Undergraduate Nursing Students. South African Journal of Higher Education 28(6): 1840-1860.

Lincoln YS, Guba EG (2000) Paradigmatic Controversies, Contradictions, and Emerging Confluences. In NK Denzin, YS Lincoln (Eds) Handbook of Qualitative Research, $2^{\text {nd }}$ ed., 163-188. Thousand Oaks, CA: Sage Publications.

McHugh CM, Frieze HI (2006) Intimate Partner Violence: New Directions. Annals New York Academy of Sciences 1087(1): 121-141

Moosa Z (2012) Violence against Women and Girls in the Post-2015 Framework: Why and how. Action Aid: https://bit.ly/2yP9Qgv.

Nabors EL, Jasinski JL (2009) Intimate Partner Violence Perpetuation among College Students: The Role of Gender Role and Gendered Violence Attitudes. Feminist Criminology 4(1): 57-82.

Truman JL, Morgan RE (2016) Criminal Victimization, 2015. Bureau of Justice Statistics.

Umana JE, Fawole OI, Adeoye IA (2014) Prevalence and Correlates of Intimate Partner Violence towards Female Students of University of Ibadan, Nigeria. BMC Women's Health 14(131): 1-8.

Wingood MG, DiClemente JR, Raj A (2000) Adverse Consequences of Intimate Partner Abuse among Women in Non-urban Domestic Violence Shelters. American Journal of Preventive Medicine 19(4): 270-275.

World Health Organization (2012) Understanding and Addressing Violence against Women. Report on Intimate Partner Violence. 